\title{
Study on the Corrosion Inhibition Performance of a Schiff Base for Carbon Steel in 1 M HCl Solution
}

\author{
Xiumei Wang ${ }^{*}$, Jiani Xing and Zongquan Huang \\ Shenyang Jianzhu University, Shenyang, 100168, China \\ *E-mail: xmwang@alum.imr.ac.cn
}

Received: 17 May 2021 / Accepted: 9 July 2021 / Published: 10 August 2021

\begin{abstract}
To investigate the corrosion of carbon steel in acidic media, weight loss measurements, electrochemical methods, thermodynamic adsorption isotherms and scanning electron microscopy (SEM) observations were adopted to study the Schiff base N,N'-bis(4-hydroxy-benzylidene)-triethylenetetramine (N,N'BHMTT) as a corrosion inhibitor for carbon steel in $1 \mathrm{M} \mathrm{HCl}$. The corrosion inhibitor exhibited excellent performance. The corrosion inhibition efficiency was as high as $82.5 \%$ at $25 \mathrm{mg} \mathrm{L}^{-1} \mathrm{~N}, \mathrm{~N}^{\prime}-\mathrm{BHMTT}$ (weight loss result). The corrosion inhibitor simultaneously slowed the cathodic and anodic corrosion processes of carbon steel. N,N'-BHMTT is a mixed corrosion inhibitor with an almost unchanged corrosion potential. The adsorption of N,N'-BHMTT on the surface of carbon steel obeyed the Langmuir adsorption isotherm along with a mixture of physical and chemical adsorption, forming a complete and dense protective film on the carbon steel surface that acted as a barrier to inhibit corrosive media from effectively contacting the carbon steel surface.
\end{abstract}

Keywords: corrosion, carbon steel, $1 \mathrm{M} \mathrm{HCl}$ solution, corrosion inhibitor, Schiff base

\section{FULL TEXT}

(C) 2021 The Authors. Published by ESG (www.electrochemsci.org). This article is an open access article distributed under the terms and conditions of the Creative Commons Attribution license (http://creativecommons.org/licenses/by/4.0/). 